\title{
Aprendiendo y aplicando la investigación en psicología
}

\author{
Carolina Vázquez Montés*
}

vazquez_carolina@hotmail.com

Álvaro Ascay Aguillón y José Armando Peña Moreno

Trillas, 2006

"La ciencia es el antídoto para el veneno del apasionamiento y la superstición", es precisamente esta cita de Adam Smith la que da inicio a la obra en la que Ascay y Peña pretenden llevar al lector al conocimiento y reflexión acerca de la importancia del conocimiento científico en el área de la psicología. Este texto se presenta bajo un formato tipo manual, en el que los autores buscan contribuir al desarrollo de habilidades teórico-prácticas en los estudiantes de psicología; dado que el desarrollo de éstas constituye un apoyo fundamental en la realización de investigaciones exposfacto sobre el comportamiento humano.

La ciencia, definida como proceso de búsqueda y sistematización del conocimiento y comprensión de los fenómenos naturales, implica el procedimiento de la investigación y a éste último se avoca la obra. Actualmente, la realidad nacional de nuestro país impone la necesidad de fomentar la investigación en toda disciplina universitaria, no sólo como cometido esencial del quehacer de la universidad sino como compromiso social. Todos aquellos quienes pretenden lograr una licenciatura en psicología, en la gran mayoría de instituciones de nuestro país tendrán que cumplir con el requisito de elaborar una tesis profesional, la cual posteriormente sustentarán frente al sínodo. En fechas recientes se ha cuestionado el valor de las tesis como única opción de titulación, ante lo cual se han ido incorporando nuevas y distintas opciones para lograrlo. Sin embargo, éstas no deberían repercutir en demérito de la investigación científica, no debería por tal considerarse como un requisito para titularse, sino como el último y más trascendente trabajo formativo que exige la carrera universitaria; solamente de esta forma contribuiremos a la difusión científica en México.

En aras de la contribución sobre todo de la aplicación de la investigación, los autores abordan una serie de temas con el sentido de compartir conocimientos muy generales acerca de contenidos necesarios para los estudiantes de nivel licenciatura. Los tres primeros capítulos los dedican tanto a fundamentos como a cuestiones éticas, de manera muy somera abordan las implicaciones actuales de la investigación. El ordenamiento de los siguientes capítulos lleva la misma 
secuencia que necesitaría un estudiante que ha decidido emprender un estudio de investigación, inicia con ideas acerca de cómo generar ideas para seleccionar un tema, hasta cómo seleccionar la muestra, explicando cómo elaborar el marco teórico y algunas cuestiones metodológicas. Justo cuando el texto lleva por buen camino la resolución de todas las interrogantes que podrían aparecer en el investigador, los autores deciden terminar su obra sin abordar puntos fundamentales como son la elaboración de los resultados, el capítulo de

discusión o la explicación del formato al que debemos de apegarnos los psicólogos. Pareciera como si el texto estuviera dirigido a alumnos de los primeros semestres, en los cuales sólo abordan los fundamentos de la investigación y no la llevan a cabo de manera formal, o acaso para algún alumno de últimos semestres, el cual necesitaría del complemento de otro texto de investigación para poder concluir su tesis.

Reconozco, sin embargo, dos aspectos valiosos de este texto. El primero de ellos es el énfasis en la praxis de lo tratado durante los distintos capítulos. Al final de cada uno de ellos, los autores incluyeron una serie de ejercicios para poner en práctica lo abordado de manera teórica en páginas anteriores. Estos ejercicios cuentan con un formato tal, que permite su contestación en el propio libro, lo que facilita la adopción del texto por parte del docente asignado a la materia de investigación, lo cual fomentaría una sistematización que facilita el aprendizaje de estos contenidos básicos. Cabe resaltar en este punto que las temáticas hipotéticas con las que están elaborados los ejercicios, resultan de interés directo para el estu-diante de psicología, pues se refieren a temas que se encuentran contenidos en la currícula de la carrera. La segunda característica valiosa, es que Ascary y Peña basan todo su texto en temas tratados por otros libros de investigación los cuales gozan del reconocimiento de la comunidad científica desde hace varios años, como son el de Kerlinger o el de Bauer, frente a los cuales la comparación con este texto resultaría por calificarlo de manera bondadosa, como light e incompleto. 